Revista de la red interuniversitaria de estudios sobre las literaturas rioplatenses contemporáneas en Francia

$10 \mid 2014$

El XIX en el XX

\title{
Introducción a los fragmentos seleccionados
}

Laura Gentilezza, Adrián Ponze y Ricardo Torre

\section{OpenEdition}

\section{Journals}

\section{Edición electrónica}

URL: https://journals.openedition.org/lirico/1718

DOI: $10.4000 /$ lirico. 1718

ISSN: 2262-8339

Editor

Réseau interuniversitaire d'étude des littératures contemporaines du Río de la Plata

\section{Referencia electrónica}

Laura Gentilezza, Adrián Ponze y Ricardo Torre, «Introducción a los fragmentos seleccionados »,

Cuadernos LIRICO [En línea], 10 | 2014, Publicado el 15 marzo 2014, consultado el 17 abril 2022. URL: http://journals.openedition.org/lirico/1718 ; DOI: https://doi.org/10.4000/lirico.1718

Este documento fue generado automáticamente el 17 abril 2022.

\section{cc) (i) (2)}

Cuadernos LIRICO está distribuido bajo una Licencia Creative Commons Atribución-NoComercialSinDerivar 4.0 Internacional. 


\title{
Introducción a los fragmentos seleccionados
}

\author{
Laura Gentilezza, Adrián Ponze y Ricardo Torre
}

$1 \quad$ ¿Por qué reescribir el siglo XIX en el xx ? Podríamos pensar simplemente que en el XIX se consolidan las instituciones y la organización nacional en ambas orillas del Río de la Plata y que, como dice Barthes,

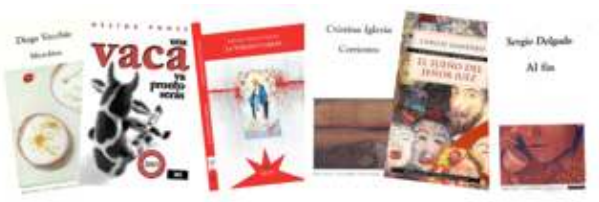
no hay nada de sorprendente en que un país vuelva sobre los objetos de su pasado y los describa nuevamente para saber qué puede hacer con ellos. Así deberían funcionar los procedimientos regulares de evaluación, afirma Barthes, categórico, en Critique et Vérité1. En esta vuelta hacia ciertos objetos literarios no hay, sin embargo, una mera descripción evaluativa.

2 La práctica y la reflexión de esta reescritura supone la confluencia de tres momentos: reescribir el siglo XIX en el xx pero pensarlo desde el siglo xxI. O, dicho de otro modo, percibir desde los primeros años del siglo xxI la manera en que el xx se sirvió del XIX para pensarse a sí mismo. Un ejercicio de autorreflexión que también es como un barajar y dar de nuevo : ponerle a la tradición los puntos sobre las íes.

3 Los fragmentos que presentamos apuestan por esa práctica. En el caso de Néstor Ponce, su novela Una vaca ya pronto serás (2006) construye el relato de un cura italiano evangelizador de la barbarie. Como el autor lo explica en "El siglo xix y ¿yo ?", la vuelta al siglo xIx tiene que ver con un deseo de pensar el presente y comprenderlo. Su narrativa intentará construir una lengua que dé cuenta de ese siglo, en parte gracias al cronotopo de esas historias, como también lo había hecho en La bestia de las diagonales (1999). La reescritura es también escritura de esa lengua del pasado, una pura imaginación. Ponce vive en Francia desde 1979, es profesor en la Universidad Rennes II y miembro de la cátedra mexicana Juan Rulfo.

4 En la misma línea trabaja Carlos Gamerro con El sueño del señor juez (2000). El viaje en este caso recorre el camino inverso al de Ponce : el juez sueña que visita la Ópera de París pero la civilización le muestra su cara menos esperada. En Buenos Aires, Gamerro 
es docente de la Universidad de San Andrés y del MALBA. Su novela Las islas (1998), reeditada en 2007 y llevada al teatro en 2011, ha reorientado la reflexión crítica en torno a la cuestión de las islas Malvinas.

5 Entreverando el siglo xIX en una imagen especular, como si los personajes y las citas del siglo de la gauchesca sirvieran para volver más aguda la mirada sobre el presente, Gabriela Cabezón Cámara enhebra el Martín Fierro y La Refalosa en el romance que cuenta la muerte del Torito, uno de los personajes de su novela La Virgen Cabeza, publicada en 2009. La reescritura de Cabezón Cámara sobrepasa el siglo con referencias a la Antigüedad clásica y al primer Renacimiento, a través de un juego con el Cancionero de Petrarca, pero es además en la métrica donde el poema culto en arte mayor se traduce en poesía popular, en octosílabo tradicional, para contar la vida del Torito, el outlaw de nuestros tiempos. En esta revisión de los objetos del pasado, el procedimiento de evaluación del canon literario reivindica asimismo, desde la lengua, las prácticas populares. El spanglish de la narración es también la reescritura de la lengua gauchesca :

\begin{tabular}{|l|l|}
\hline para el Torito la vida & Si uno aguanta, es gaucho bruto ; \\
from beginning to the end & si no aguanta, es gaucho malo. \\
siempre fue una res jodida & Dele azote, dele palo, \\
y lo hicieron fenecer & [sic] porque es lo que necesita ! \\
en un cayo de Florida & De todo el que nació gaucho \\
(La Virgen Cabeza, págs. 101-102) & esta es la suerte maldita \\
& (La vida del gaucho Martín Fierro, pág.55) \\
\hline
\end{tabular}

6 La unión de citas y de formas de la tradición, trabajadas con la masa de una lengua mestiza, narra la miseria de finales del siglo xx, que, al parecer, no está tan lejos de la miseria de los años de la fundación.

7 À rebours de la solemnidad que podría enmarcar la reescritura de la tradición, "El hombre de los sesos" y los otros cuentos de Diego Vecchio compilados en Microbios adoptan una óptica delirante y paródica que toma el discurso del siglo xIX como objeto de una escritura absolutamente contemporánea. El positivismo y el discurso cientificista del naturalismo están al servicio del análisis del cuerpo literario: un cuerpo que escribe. En "El hombre de los sesos", el protagonista es un escritor argentino que pierde el lenguaje. El proceso de recuperación y su nuevo glosario de palabras degradan la tradición "del matadero" al léxico restringido de la carnicería. Diego Vecchio reside en Francia desde 1992 y enseña en la Universidad Paris 8 Vincennes - Saint-Denis. Su libro Osos fue recientemente traducido al francés.

8 El escritor santafesino Sergio Delgado, profesor en la Universidad de Bretagne-Sud, se inscribe, según Analía Gerbaudo, entre los herederos de Juan José Saer por "el carácter siempre incompleto y fragmentario de aquello que en principio puede aparecer como un todo, como una unidad, como un origen". En el texto de Al fin que incluimos, observamos una huella de lo que Gerbaudo señala en su artículo con respecto a una reflexión de Ricardo Piglia: “Tal vez en los ' 80 era necesario pensar en un texto lo suficientemente radical como para ponerse en serie con el Facundo. Después de los ' 90 es probable que en Argentina se necesite reinventar la forma de pensar lo político y, más puntualmente, lo político en la literatura y lo que puede la literatura en este orden de cosas. Encuentro en la escritura de Sergio Delgado esa doble operación, entre el don, la reinvención y la deuda"2. 
9 Cabría señalar aquí que uno de los puntos de convergencia entre Sergio Delgado, Gabriela Cabezón Cámara, Carlos Gamerro y Néstor Ponce es la crítica a la dicotomía civilización-barbarie impulsada por Domingo Sarmiento y afirmada por los liberales argentinos de la generación de 1837. Describiendo escenarios o reescribiendo hechos ocurridos en la segunda mitad del siglo xIx, como la avanzada del ejército sobre los nativos -la mal llamada "campaña del desierto"-, los escritores que aquí presentamos se remontan hasta el siglo xix y retoman el paradigma del mestizaje latinoamericano para introducirlo en el campo literario argentino ; idea que escritores como Juan Carlos Dávalos, Carlos Hugo Aparicio, Ricardo Rojas y David Viñas defendieron, cada uno a su turno, a lo largo del siglo XX. ${ }^{3}$

10 En algunos casos, como en los fragmentos escogidos de las novelas de Gamerro y Ponce $^{4}$, se establece una relación entre el pasado y el presente histórico a través del debate sobre la identidad nacional vigente durante los años de la formación de la nación y que fue retomado en los años que siguieron al retorno de la democracia (1983) para alcanzar su apogeo con el cambio de milenio. El texto de Carlos Gamerro, que forma parte de un libro sobre la literatura argentina y el imaginario nacional que será publicado por Penguin Random House en el 2015, nos parece un buen ejemplo de este trabajo.

11 ¿Se mira con los ojos? El fragmento "Mirar el campo" de Cristina Iglesia impone desde su propia cadencia la lectura pausada de los textos escritos al ritmo de una lengua segunda. Es la posibilidad de ver, desde una perspectiva modificada por sus lecturas y su trabajo crítico como titular de la cátedra de Literatura Argentina del siglo XIX en la Universidad de Buenos Aires, lo que la autora puede desplegar en este libro de relatos, Corrientes, volviendo sobre los espacios de la infancia y de la lengua primera y abriendo, desde el siglo XXI, la intimidad del recuerdo del siglo XX.

Reescribir el siglo es para estos autores recorrerlo nuevamente, dejarse atravesar por su voz e inscribirla en la lengua de su cuerpo.

\section{NOTAS}

1. Barthes, Roland (1966). Critique et vérité. Ed. du Seuil, Paris.

2. Gerbaudo, Analía. "Sarmiento, Saer y Sergio Delgado : escritores de su tiempo". En : Revista Arena - año 0, número 1, Universidad Nacional de Catamarca, 2010-2011.

3. Consultar con relación a este tema: Moyano, Elisa. "Mestizaje y nacionalismo en la tierra en armas de Dávalos / Serrano y en algunos ensayos de Juan Carlos Dávalos (2003)”. En : Andes, núm. 14, Universidad Nacional de Salta, Argentina. http://www.redalyc.org/pdf/127/12701407.pdf

4. Cf. : Olivieri-Godet, Rita. "A ficção da nação entre sonhos e pesadelos", Amerika [En línea], 4 | 2011, puesto en línea el 21 de junio de 2011, consultado el 27 de febrero de 2014. URL : http:// amerika.revues.org/2121 